\title{
A PRE-FORMED PAEDIATRIC OROTRACHEAL TUBE DESIGN BASED ON ANATOMICAL MEASUREMENTS
}

\author{
G.A.R. Morgan AND D.J. STEWARD
}

\begin{abstract}
A pre-shaped, pre-cut paediatric orotracheal tube was designed from data obtained from a study of airway length and configuration in children of various ages. This tube is intended for use in head and neck, and pharyngeal surgery.
\end{abstract}

KEY WORDS: EQUIPMENT, tubes, paediatric orotracheal.

THE USE of a pre-formed tracheal tube minimizes the probability that kinking will occur after insertion ${ }^{1}$ and lessens the possibility that undue pressure will be exerted on adjacent anatomical structures. ${ }^{2}$ When pre-formed tracheal tubes are used for paediatric patients the shape must conform to the airway and, additionally, the length must be carefuly planned if the possibility of endobronchial advancement or accidental extubation is to be avoided. This is especially important when considering the short length of the trachea in infants and small children, and the effect of movement of the head on the position of the intratracheal tip of the tracheal tube. ${ }^{3}$ The R.A.E. pre-formed tube* was designed by intentionally intubating the right main stem bronchus and then withdrawing the tube. ${ }^{4}$ The maximal length to which the tube could be inserted without resulting in bronchial intubation was confirmed by $x$-ray, and thus the appropriate length for each diameter of tube was established. The tip of the R.A.E. tube is provided with two additional "eyes" to provide for ventilation if the tube is advanced too far.

We have designed an orotracheal tube which offers the advantages of a pre-formed tube and,

G.A.R. Morgan M.B., B.S., F.F.A.R.C.S., Fellow in Anaesthesia, D.J. Steward M.B., B.S., F.R.C.P.(C), Anaesthetist-in-Chief, Department of Anaesthesia, The Hospital for Sick Children, Toronto, Ontario, Canada. Department of Anaesthesia, University of Toronto, Canada.

Reprint requests to: Dr. D.J. Steward, Department of Anaesthesia, The Hospital For Sick Children, 555 University Avenue, Toronto, Ontario M5G 1X8.

Dr. Morgan's Piesent Address: Senior Registrar in Anaesthesia, Bristol Royal Infirmary, Bristol BS2 8HW, Avon, England.

*R.A.E. Tube, National Catheter Corporation, Argyle, N.Y. 12809, U.S.A. in addition, is based on the anatomical measurements of the airway. The linear dimensions of the airways of groups of normal children were measured from existing radiographs or during bronchoscopy. ${ }^{5}$ The diameter of the tracheal tube for each age group was calculated on the basis of the formula:

$$
\text { internal diameter (I.D.) }=\frac{16+\text { Age (years) }}{4}
$$

Each size of tube was then designed so that the lengths of each segment would be appropriate for the intended age, and the intratracheal tip would lie at a point midway between the vocal cords and the carina. Table I shows the dimensions of the tracheal tubes of sizes from $4.5 \mathrm{~mm}$ I.D. to $8.0 \mathrm{~mm}$ I.D. Templates for each size of tube were drawn from $\mathrm{x}$-rays onto squared paper and the tubes were manufactured in polyvinyl chloride.* Figure 1 shows the tube alongside an Oxford tube ${ }^{1}$ and a R.A.E. tube. ${ }^{4}$

Table II shows the sizes of tracheal tubes which may be expected to fit normal children between 3 and 16 years of age, together with normal height and weight at each age. The distance from incisor teeth to mid-trachea along the path taken by a tracheal tube is also shown. Children with some surgical conditions may be inappropriately developed for their age and, in this case, height or weight is a better guide than age in selecting the optimal tube length. ${ }^{5}$ All children are different, however, and the anaesthetist must consider every aspect of each patient in selecting a tracheal tube and, having inserted it, must carefully confirm that it does fit appropriately.

*Portex Industries Ltd., 1361 Huntingwood Drive, Toronto, Ontario, Canada. 
TABLE I

Basic Dimensions of the Tracheal Tube Described Taken from Upper Airway Dimensions of Normal Males

\begin{tabular}{lcccccccc}
\hline Internal diameter (mm) & 4.5 & 5.0 & 5.5 & 6.0 & 6.5 & 7.0 & 7.5 & 8.0 \\
\hline Chin - Lips (cm) & 5.0 & 5.2 & 5.25 & 5.25 & 5.5 & 5.75 & 6.0 & 6.25 \\
Lips - C $(\mathrm{cm})$ & 8.0 & 8.5 & 8.75 & 8.75 & 9.0 & 9.5 & 10.0 & 10.5 \\
C $_{2}$ - Cords (cm) & 3.0 & 3.5 & 4.0 & 4.5 & 4.75 & 5.25 & 6.25 & 7.0 \\
Cords - tube end (cm) & 4.0 & 4.5 & 5.0 & 5.0 & 5.5 & 6.0 & 7.0 & 8.0 \\
Total tube length (cm) & 20.0 & 21.7 & 23.0 & 23.5 & 24.75 & 26.5 & 29.25 & 31.75 \\
Angles - Degrees & & & & & & & & \\
Pharynx $\beta$ & 75 & 75 & 80 & 80 & 80 & 80 & 80 & 85 \\
Chin $\alpha$ & 65 & 65 & 70 & 70 & 75 & 75 & 75 & 75 \\
\hline
\end{tabular}

TABLE II

Table of Internal Diameters of Tracheal Tubes, Ages, Heights, Weights and Suggested Suitable Tracheal Tube Length as Given by Distance from Teeth to Mid-Trachea

\begin{tabular}{lcccccccccccccc}
\hline \hline Age yrs. & 3 & 4 & 5 & 6 & 7 & 8 & 9 & 10 & 11 & 12 & 13 & 14 & 15 & 16 \\
\hline Height $\mathrm{cm}$ & 100 & 105 & 110 & 115 & 125 & 130 & 135 & 140 & 143 & 145 & 155 & 165 & 168 & 170 \\
Weight kg & 16 & 18.5 & 21.0 & 22.5 & 26.0 & 30.0 & 32.0 & 36.5 & 38.0 & 40.0 & 50.0 & 55.0 & 57.5 & 70.0 \\
Tube size I.D. (mm) & 4.5 & 5.0 & $5.0-$ & 5.5 & $5.5-$ & 6.0 & $6.0-$ & 6.5 & $6.5-$ & 7.0 & $7.0-$ & 7.5 & $7.5-$ & 8.0
\end{tabular}

Teeth to

$\begin{array}{lllllllllllllll}\text { mid-trachea (cm) } & 14.5 & 15.0 & 15.5 & 16.5 & 17.0 & 18.0 & 18.5 & 19.0 & 19.5 & 20.0 & 21.0 & 22.0 & 23.5 & 24.5\end{array}$

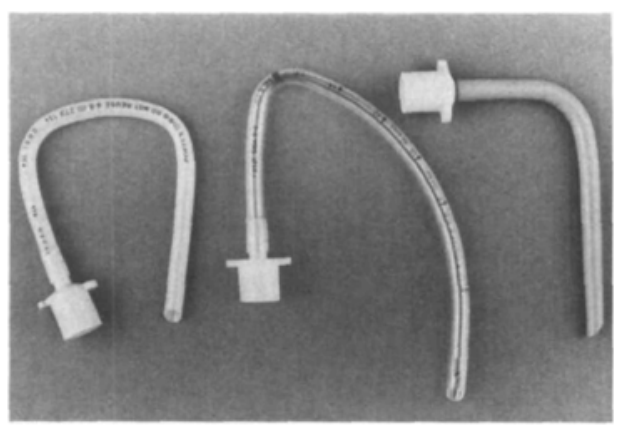

Figure 1. New design orotracheal tube (left) alongside R.A.E. tube (centre) and Oxford tube (right).

Figure 2 shows a radiograph of a patient with the tracheal tube in place. The shape of the tube matches the shape of the airway and therefore it exerts little pressure on adjacent structures while in place. It is noteworthy that this tube is almost exactly the same shape on removal as it was on insertion, demonstrating that very little moulding of the tube by the tissues lining the airway has been necessary.

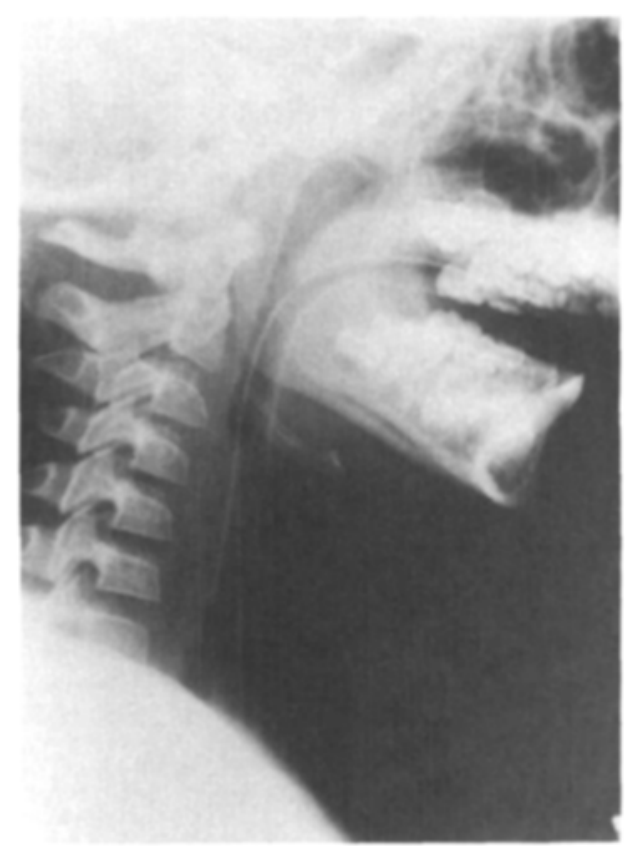

FIGURE 2. Radiograph of the orotracheal tube in position. 


\section{CONCLUSION}

A paediatric orotracheal tube has been designed using measurements taken from living children. The use of this tube should ensure minimal pressure on adjacent tissues and accurate placement of the distal tip of the tube.

\section{REFERENCES}

1. Alsop, A.F. Non-kinking endotracheal tubes. Anaesthesia 10: 401-403, 1955.
2. Lindholm, C.E. Experience with a new endotracheal tube. Acta Otolaryngology 75: 389$390,1973$.

3. Bosman, Y.K. \& Foster, P.A. Endotracheal intubation and the head posture in infants. South African Med. J. 52: 71-73, 1977.

4. Ring, W.H., Adair, J.C. \& Elwyn, R.A. A new paediatric endotracheal tube. Anaesthesia and Analgesia, Current Researches 54: 273$274,1975$.

5. Morgan, G.A. \& Steward, D.J. Airway dimensions in children with and without cleft palate. Can. Anaesth. Soc. J. 29: 1-8 (1982).

\section{RÉSUMÉ}

Un tube orotrachéal à usage pédiatrique à courbures pré-moulées (pre-formed tube) a été mis au point à partir des résultats d'une étude sur la longueur et la configuration des voies aériennes d'enfants d'âges variés. Ce tube a été conçu en vue de la chirurgie de la tête, du cou et du pharynx. 